\title{
The electrocardiogram is a more sensitive indicator than echocardiography of hypertrophic cardiomyopathy in families with a mutation in the MYH7 gene
}

Sahar Al-Mahdawi, Susan Chamberlain, Lidia Chojnowska, Eva Michalak, Petros Nihoyannopoulos, Mark Ryan, Beata Kusnierczyk, Julie A French, David M Gilligan, John Cleland, Robert Williamson, Witold Ruzyllo, Celia Oakley

\begin{abstract}
Background-Mutations in the cardiac $\beta$ myosin heavy chain gene causing hypertrophic cardiomyopathy have been identified, and to assist both diagnosis and prediction of outcome attempts have been made to correlate phenotype and genotype. Two new mutations in codon 403 of the gene in three unrelated families are described and attention drawn to variable or even absent phenotypic expression in different family members. Methods and results-The polymerase chain reaction and heteroduplex analysis on Mutation Detection Enhancement gels were used to search for mutations in the globular head of the $\beta$ myosin heavy chain gene in families with hypertrophic cardiomyopathy. Two mutations were found in exon 13 (codon 403) of the gene. In two unrelated Polish families the mutation resulted in the conversion of arginine to tryptophan (CGG $\rightarrow$ TGG). A second mutation, found in a British family, converted the same arginine to leucine (CGG $\rightarrow$ CTG). These mutations were detected in family members who had electrocardiographic and echocardiographic features typical of hypertrophic cardiomyopathy; however, they were also detected in 7 other adult relatives with an abnormal electrocardiogram but a normal echocardiogram. Two unrelated adult relatives had completely normal clinical findings but carried the gene mutation.
\end{abstract}

Conclusions-Identification of a specific mutation gives no guide to the clinical phenotype. There is considerable variability in the phenotypic expression of hypertrophic cardiomyopathy. Mutations were detected in adults previously regarded as normal or in whom the diagnosis was questionable. The fact that the clinical significance of the mutation in these people is still unknown emphasises the dilemma facing screening programmes. Isolated, unexplained electrocardiographic abnormalities in first degree relatives in a family with a definitive diagnosis of hypertrophic cardiomyopathy should be regarded as evidence of a carrier state.

(Br Heart F 1994;72:105-111)
Hypertrophic cardiomyopathy (HCM) is characterised by unexplained hypertrophy of the non-dilated left ventricle with myocyte and myofibrillar disarray. ${ }^{2}$ The clinical diagnosis is based on physical examination, electrocardiography, and echocardiography showing an increase in left ventricular wall thickness. The clinical features are not always remarkable and in some cases minor abnormalities lead to a doubtful diagnosis. The apparent coexistence of HCM with hypertension, athletic training, old age and AfroCaribbean origin confuses the issues.

The demonstration of linkage to the MYH7 locus on chromosome 14q11-q12 and subsequent identification of mutations associated with the disease has facilitated genetic diagnosis in some affected families. ${ }^{45}$ Recent reports of the assignment of a further three loci on chromosome $1 \mathrm{q} 3,{ }^{6} 11,{ }^{7}$ and $15 \mathrm{q} 2^{8}$ confirm the genetic heterogeneity of this complex disease.

The proportion of pedigrees with HCM caused by mutation at each of these loci remains to be established. Consequently, analysis of new families presenting for diagnosis and genetic counselling is not straightforward, particularly as the proximity of markers to these new loci, with the exception of the MYH7 gene, is not yet close enough to allow their accurate use. The situation is further complicated by the fact that most families are not large enough or have a suitable structure for conventional linkage analysis, especially if the pedigrees include equivocal cases. Systematic screening of the entire exon complement of MYH7 is then necessary.

Attempts have been made to correlate genotype with clinical manifestations in families with mutations in MYH7, both in terms of prognosis and to identify earliest signs of the disease. Watkins et al reported a correlation between the nature of the amino acid substitution, net charge change, and prognosis. ${ }^{4}$ They suggested that a change in charge leads to an unfavourable prognosis. Subsequent studies, however, showed that different missense mutations in the globular head of the MYH7 gene can give rise to similar

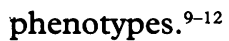

We report two new mutations in exon 13 of the MYH7 gene in three families that illustrate a full range of phenotypic heterogeneity and the problems faced by clinicians. As well 
as patients with definitive clinical HCM, these families include members showing only partial expression of the mutation or no detectable abnormality. It remains difficult to predict the outcome in each gene carrier because before the introduction of DNA analysis this variable phenotypic expression was not recognised.

\section{Patients and methods \\ CLINICAL ANALYSIS}

Three white Europeans were seen as part of a collaborative study to identify the genetic defect giving rise to HCM. A total of 27 family members were evaluated by clinical history, physical examination, 12 lead electrocardiogram, and echocardiography (Hewlett Packard Sonos 1000 and 1500 and Toshiba Sonolayer SSH-160A ultrasound scanners). Standard two dimensional images from the parasternal long and short axis and apical four chamber views were examined for left ventricular hypertrophy and to assess its distribution. Continuous and pulsed wave Doppler examinations were used to assess left ventricular filling characteristics and left ventricular outflow tract velocities. An unexplained left ventricular end diastolic wall thickness of $\geqslant 13 \mathrm{~mm}$ was deemed abnormal. These criteria were adjusted for age and weight. Electrocardiograms were analysed according to standard criteria. ${ }^{13}$ There was no history or evidence of hypertension or athletic training in any family member. A confident clinical diagnosis of HCM was made when echocardiography showed unexplained hypertrophy. A tentative diagnosis of $\mathrm{HCM}$ was made when there was an electrocardiographic abnormality but no echocardiographic evidence of hypertrophy.

CLINICAL DESCRIPTION

The table summarises the clinical details in the three families.

\section{Family $A$}

Clear clinical features of HCM were recognised in the proband (III/3) in this Polish family (fig 1A) when she was 15 . For 4 years she had complained of atypical chest pains, shortness of breath (NYHA II) and palpitation on exertion. Physical examination showed a systolic ejection murmur at the left sternal edge. The electrocardiogram showed inferolateral ST/T wave abnormalities and there was severe asymmetrical left ventricular hypertrophy on echocardiography with an interventricular septal wall thickness (IV SWT) of $40 \mathrm{~mm}$ compared with a posterior wall thickness (PLVWT) of $10 \mathrm{~mm}$. There was no systolic anterior motion of the mitral valve or left ventricular outflow tract (LVOT) obstruction, though colour Doppler showed mild mitral regurgitation. On exercise testing her performance was limited by dyspnoea and the blood pressure response was flat. Holter monitoring did not show any important arrhythmias. She was treated with verapamil and her condition remained stable for at least 4 years.

All other cases in the family were detected during the course of family screening. The proband's grandmother, (I 1) aged 67, was symptom free apart from shortness of breath (unrelated to exertion) but she had typical asymmetrical left ventricular hypertrophy (IVSWT $16 \mathrm{~mm}$ ) on echocardiography, with inferior $Q$ waves on the electrocardiogram.

The proband's mother (II/2), screened at 40 , had symptoms of chest pain, shortness of breath (NYHA III), palpitation, and syncope on exertion. Her physical examination was normal but she had lateral $Q$ waves on the electrocardiogram, and echocardiography showed asymmetrical left ventricular hypertrophy (IVSWT $19 \mathrm{~mm}$ ).

The proband's brother (III/5) was symptom free when initially screened at the age of 9 with normal physical examination but had evidence of left ventricular hypertrophy on

Comparative clinical data on carriers of the two mutations in codon 403 of the MYH7 gene

\begin{tabular}{|c|c|c|c|c|c|c|c|c|c|}
\hline \multirow[b]{2}{*}{ Patient } & \multirow[b]{2}{*}{ Age/Sex } & \multicolumn{3}{|l|}{ Symptoms } & \multirow[b]{2}{*}{$E C G$} & \multicolumn{3}{|c|}{ Echocardiogram } & \multirow[b]{2}{*}{$\begin{array}{l}\text { Clinical } \\
\text { status }\end{array}$} \\
\hline & & Chest pain & $\begin{array}{l}\text { Dyspnoea } \\
(N Y H A)\end{array}$ & Syncope & & $\begin{array}{l}I V S W T \\
(\mathrm{~mm})\end{array}$ & $\begin{array}{l}P L V W T \\
(\mathrm{~mm})\end{array}$ & Comment & \\
\hline & & & & & \multirow{2}{*}{\multicolumn{4}{|c|}{ Mutation CGG-Arg to TGG-Trp }} & \\
\hline Family A: & & & & & & & & & \\
\hline $\begin{array}{l}\text { I } 1 \\
\text { II } 2\end{array}$ & $\begin{array}{l}67 / F \\
44 / F\end{array}$ & - & + & - & $\operatorname{Inf} Q$ & 16 & 11 & Inc SAM & $\mathrm{HCM}$ \\
\hline III 2 & $\begin{array}{l}44 / F \\
22 / F\end{array}$ & $\stackrel{+}{-}$ & III & \pm & Iat $\mathbf{Q}$ & 19 & 12 & $\stackrel{N}{\mathbf{N}}$ & $\underset{N}{\mathrm{HCM}}$ \\
\hline III 3 & $19 / \mathrm{F}$ & + & II & - & $\mathrm{ST} / \mathrm{T}$ & 40 & 10 & MR & $\mathrm{HCM}$ \\
\hline III 5 & 9/M & - & - & - & LVH/inflat Q & 9 & 9 & - & Equivocal \\
\hline \multicolumn{10}{|c|}{ Family B: } \\
\hline I 1 & $79 / \mathrm{F}$ & - & - & - & Small lat $\mathbf{Q}$ & NA & NA & NA & Equivocal \\
\hline II 1 & $50 / \mathrm{F}$ & - & - & - & Small inf $\mathrm{Q}$ & 10 & 7 & & Equivocal \\
\hline II 3 & $56 / \mathrm{F}$ & - & - & - & Lat Q, LAH & 11 & 11 & & Equivocal \\
\hline III 1 & $22 / M$ & + & - & - & $\mathrm{LVH}, \mathrm{ST} / \mathrm{T}$ & 27 & 8 & SAM,MR,LVOTO & HCM \\
\hline III 2 & $19 / M$ & + & - & - & LVH, ST/T & 34 & 15 & SAM,MR,LVOTO & $\mathrm{HCM}$ \\
\hline III 3 & $28 / \mathrm{F}$ & - & - & - & & 8 & 9 & & \\
\hline & & & & & \multirow{2}{*}{\multicolumn{4}{|c|}{ Mutation CGG-Arg to CTG-Leu }} & \\
\hline Family C: & & & & & & & & & \\
\hline II 1 & $47 / M$ & - & II & - & ST/T, IRBBB & 17 & 14 & Reversed E/A & $\mathrm{HCM}$ \\
\hline II 4 & $50 / \mathrm{F}$ & - & - & - & LVH, inf Q, ST/T & 11 & 11 & & Equivocal \\
\hline $\begin{array}{l}\text { III } 1 \\
\text { III } 2\end{array}$ & $\begin{array}{l}23 / \mathrm{M} \\
19 / \mathrm{F}\end{array}$ & $\bar{z}$ & $\overline{-}$ & $\overline{-}$ & $\begin{array}{l}\mathrm{LVH}, \text { inflat } \mathrm{Q}, \mathrm{ST} / \mathrm{T} \\
\mathrm{ST} / \mathrm{T}\end{array}$ & 10 & 11 & $\mathbf{N}$ & Equivocal \\
\hline III 3 & $\begin{array}{l}19 / \mathrm{F} \\
26 / \mathrm{M}\end{array}$ & $\overline{-}$ & $\overline{-}$ & - & LVH, lat Q ST/T & $\begin{array}{r}10 \\
8\end{array}$ & $\begin{array}{r}10 \\
8\end{array}$ & N & $\begin{array}{l}\text { Equivocal } \\
\text { Equivocal }\end{array}$ \\
\hline III 4 & $24 / \mathrm{M}$ & - & - & - & LVH & 24 & 10 & SAM,MR,LVOTO & $\mathrm{HCM}$ \\
\hline III 5 & $22 / \mathrm{F}$ & + & III & + & LVH, LAH & 20 & 10 & SAM,LVOTO & $\mathrm{HCM}$ \\
\hline
\end{tabular}

HCM, hypertrophic cardiomyopathy; equivocal, abnormal ECG \& non-diagnostic echo; N, normal; IVSWT, interventricular septal wall thickness; PLVWT, posterior left ventricular wall thickness; LVH, left ventricular hypertrophy; LAH, left atrial hypertrophy; IRBBB, incomplete right bundle branch block; ST/T, ST/T wave changes; lat, lateral; inflat, inferolateral; inf, inferior; $M R$, mitral regurgitation; LVOTO, left ventricular outflow tract obstruction; reversed E/A reversed E/A ratio; inc SAM, incomplete systolic anterior motion of mitral valve; NA, not available. 
A

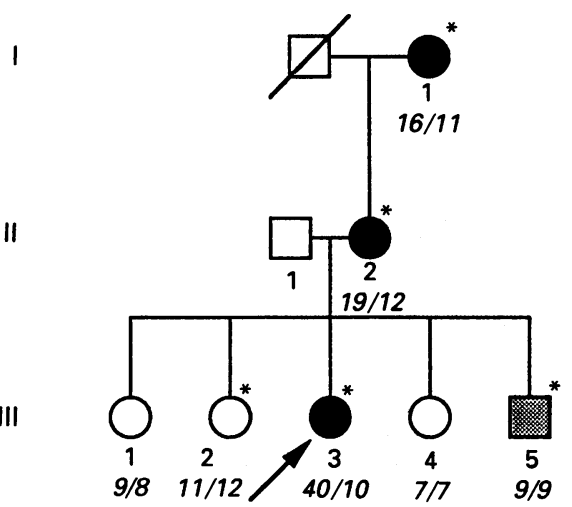

B

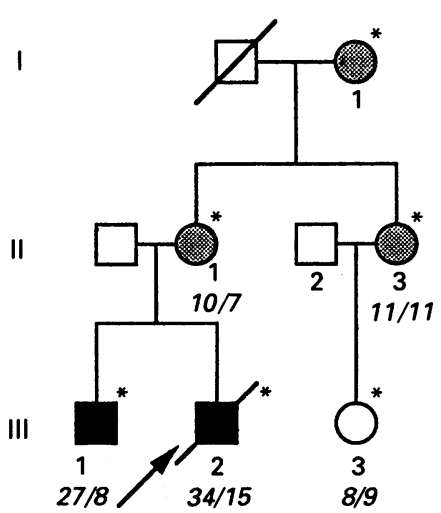

C

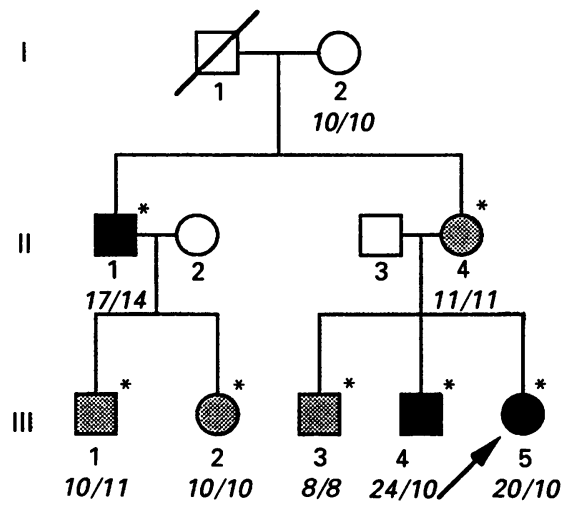

Figure 1 Pedigrees of families $A, B$, and $C$ in which hypertrophic cardiomyopathy segregates as an autosomal dominant trait. Solid symbols, affected individuals; open symbols, unaffected or unknown status; shaded symbols, individuals with an equivocal diagnosis who had abnormal electrocardiograms and normal echocardiograms; slashed symbols, deceased. Arrow indicates proband. Asterisks indicate carriers of the mutation. Numbers in italics are the interventricular septal wall thickness (IVSWT) and posterior left ventricular wall thickness (PLVWT) in mm.

electrocardiogram with small $Q$ waves inferolaterally. Echocardiography was normal. His clinical diagnosis was equivocal in view of his age and electrocardiographic abnormalities.

The proband's sister (III/2) aged 22 was symptom free with a normal physical examination, electrocardiogram, and echocardiogram. Clinically, she appeared to be unaffected.

\section{Family $B$}

In a second Polish family (fig 1B) HCM was diagnosed in the proband (III/2) when he was 9. He presented with atypical chest pains and exertional presyncope. He was active and had no other symptoms. On examination he had a systolic murmur consistent with HCM. The electrocardiogram showed left ventricular hypertrophy with widespread ST/T changes. Echocardiography confirmed asymmetrical left ventricular hypertrophy (IVSWT $34 \mathrm{~mm}$ ) systolic anterior motion of the mitral valve and left ventricular outflow tract obstruction $(3.0 \mathrm{~m} / \mathrm{s})$. When he was 19 Holter monitoring showed non-sustained ventricular tachycardia and he showed a flat blood pressure response on exercise testing. Ventricular fibrillation was induced during electrophysiological testing, and treatment with amiodarone was started. $\mathrm{He}$ collapsed and died while running to university. A necropsy was not performed.

HCM was diagnosed in a brother, (III/1) aged 22 , during family screening when he was 12. He had similar symptoms and clinical signs to III/2. He also had left ventricular hypertropy on the electrocardiogram and had an IVSWT of $27 \mathrm{~mm}$ measured on echocardiography. Holter monitoring and exercise testing were normal. He remains stable on treatment.

The proband's father could not be screened but his mother (II/1), grandmother (I/1), and maternal aunt (II/3) all had abnormal electrocardiograms (table) and normal echocardiograms. The proband's maternal cousin, III/3 aged 28, showed no evidence of the condition on physical examination, electrocardiogram, or echocardiography. She was considered to be unaffected.

\section{Family $C$}

HCM was diagnosed in the proband in this British family (III/5, fig 1C) when she was 21 . She presented with dyspnoea on exertion (NYHA III), atypical chest pain, palpitation, and syncope. She had typical signs of HCM on physical examination with evidence of a left ventricular outflow tract gradient. The electrocardiogram showed left ventricular hypertropy (fig 2) and echocardiography confirmed asymmetrical left ventricular hypertrophy (IVSWT $20 \mathrm{~mm}$ ), systolic anterior motion of the mitral valve, and a variable left ventricular outflow tract velocity of $4-6 \mathrm{~m} / \mathrm{s}$. Holter monitoring showed multifocal ventricular extrasystoles and sinus tachycardia with ST segment depression at the time of presyncope. Exercise capacity was reduced, with a maximal oxygen consumption of 20.5 $\mathrm{ml} / \mathrm{kg} / \mathrm{min}$, a flat blood pressure response, and inferolateral ST segment depression (3 mm). Despite treatment with xamoterol, verapamil, and diuretics the symptoms continued.

The rest of the family had routine family screening. Only the proband's maternal uncle (II/1) and sibling (III/4) had features typical of HCM on electrocardiogram and echocardiogram (IVSWT $17 \mathrm{~mm}$ and $24 \mathrm{~mm}$ respectively). All other members of the family had abnormal electrocardiograms (fig 2) but normal echocardiograms at the ages of 19, 23, 26 , and 50. A diagnosis could not be confirmed until the genetic analysis verified the presence of a pathogenetic mutation in these individuals.

No clinical, electrocardiographic, or echocardiographic abnormalities were detected in the three families except for a case of mild mitral valve prolapse and a case of voltage criteria for left ventricular hypertrophy on electrocardiogram in a thin, mildly athletic young man.

\section{MOLECULAR ANALYSIS}

Genomic DNA was isolated from peripheral blood by standard techniques. The exons coding for the globular head of the MYH7 gene were systematically screened by heteroduplex 

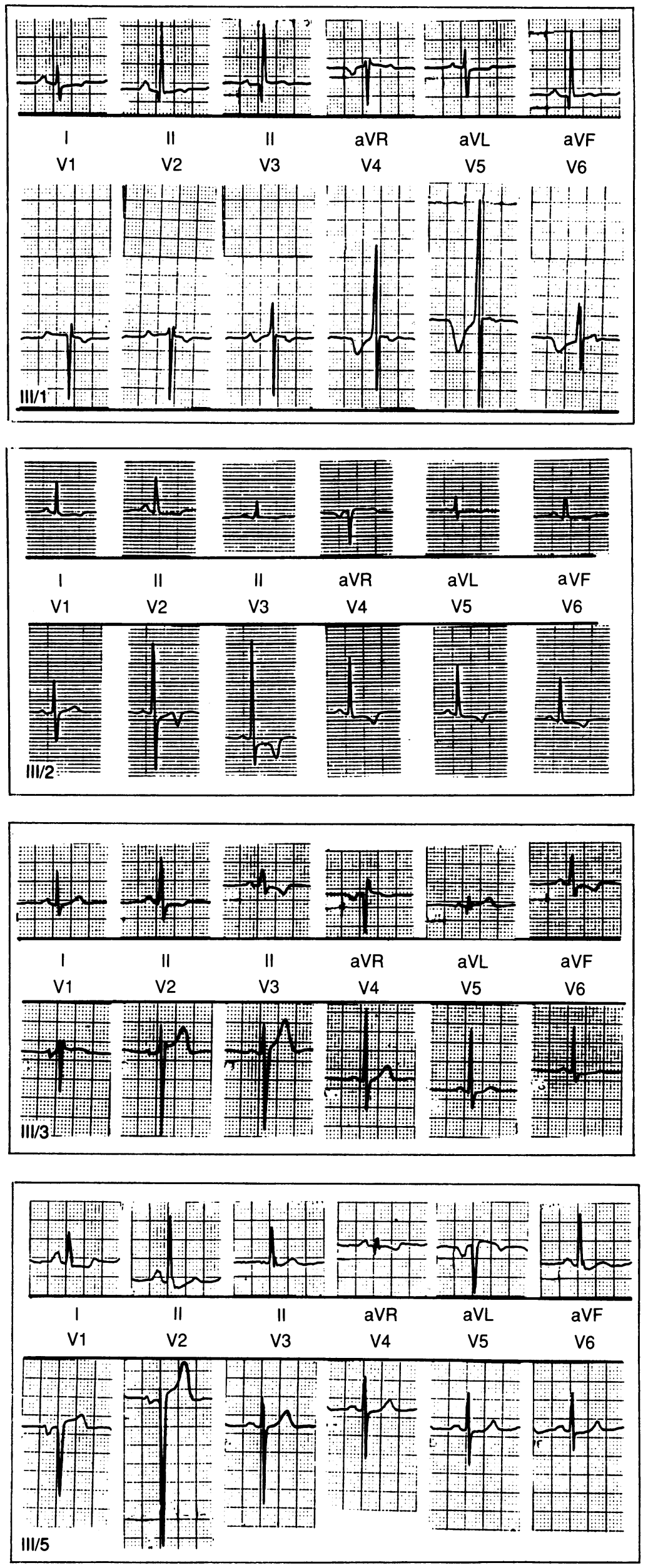

Figure 2 Electrocardiograms of the third generation of family $C$. analysis followed by direct sequencing of probands from all the HCM families.

The exons were amplified with primers designed to the flanking regions. ${ }^{14}$ The oligonucleotide primers used for polymerase chain reaction amplification of exon 13 of MYH7 are: 13F 5' GCTCTTGCCTTTTCCTTCCAG $3^{\prime}$ and $13 \mathrm{R} 5^{\prime}$ TGCTGGACATTCTGCCCCTT 3'. We used a different reverse primer for sequencing (13R2m 5' TGAGCAGGGTTGTTGGGAAG 3'). Biotinylation of one primer was required. The PCR amplification was carried out in a total volume of $50 \mu \mathrm{l}$ containing $100-200 \mathrm{ng}$ of genomic DNA, $50 \mathrm{pmol}$ each of the forward and reverse primer, $250 \mu \mathrm{M}$ each $\mathrm{dNTP}$ and 1 unit of Dynazyme Taq polymerase (Flowgen). Samples were initially denatured at $94^{\circ} \mathrm{C}$ for $10 \mathrm{~min}$, followed by 40 cycles at $56^{\circ} \mathrm{C}$ for $1.5 \mathrm{~min}, 72^{\circ} \mathrm{C}$ for $4 \mathrm{~min}, 92^{\circ} \mathrm{C}$ for $40 \mathrm{~s}$.

We used streptavidin magnetic beads (Dynal, Norway) and alkali denaturation to prepare the PCR templates required for sequencing. ${ }^{15}$ We used Sequenase Version 2 for dideoxy sequencing. Heteroduplex analysis was performed on Mutation Detection Enhancement gels (Hydrolink MDE gels, AT Biochem). PCR products were heated to $94^{\circ} \mathrm{C}$ for $5 \mathrm{~min}$, left to cool slowly to $37^{\circ}$, and then put on ice. Ten per cent of the products were loaded on non-denaturing Hydrolink MDE gels and electophoresed in $0.6 \times \mathrm{TBE}$ at $400 \mathrm{~V}$ for 11 hours. The gels were stained with ethidium bromide and visualised on a UV transilluminator.

\section{Results}

Heteroduplex analysis and direct sequencing of the PCR product corresponding to exon 13 of the MYH7 gene detected two different mutations in codon 403. The first mutation, detected in pedigrees $A$ and $B$, results in the conversion of a cytosine into a thymine residue at nucleotide position $1293^{16}$ within exon 13 (fig 3A). This base substitution converts arginine (CGG) to tryptophan (TGG) at amino acid position 403 with an alteration in charge from +1 to 0 . In the second mutation, detected in pedigree $C$, guanine replaced thymine (fig 3B) at nucleotide position $1294,{ }^{16}$ converting the arginine 403 (CGG) into a leucine (CTG) and changing the charge from +1 to 0 .

Neither mutation was seen in 100 normal chromosomes or in 48 other unrelated HCM chromosomes. Analysis of the sequence in the immediate vicinity of the substitution predicted that whereas both mutations result in the abolition of an Ava I site, the first mutation creates a Pfl MI site and the second a Sty I restriction site. Direct digestion of the PCR product of genomic DNA is therefore an independent and rapid method of detection.

Figure 4A shows the Ava 1 digestion of the PCR amplified product corresponding to exon 13 in family A. Digestion of the product from a normal individual with this enzyme generates two fragments 90 and $49 \mathrm{bp}$ in size 
Figure 3 Direct sequencing of the amplification product of exon 13 of the MYH7 gene. Sequence comparisons between an affected and a normal individual in $(A)$ family $A$, showing the CGGTGG (arginine to tryptophan) substitution (this mutation was also detected in family $B$ ), and (B) Family $C$, showing the mutation CGG-CTG (arginine to leucine) substitution.
A

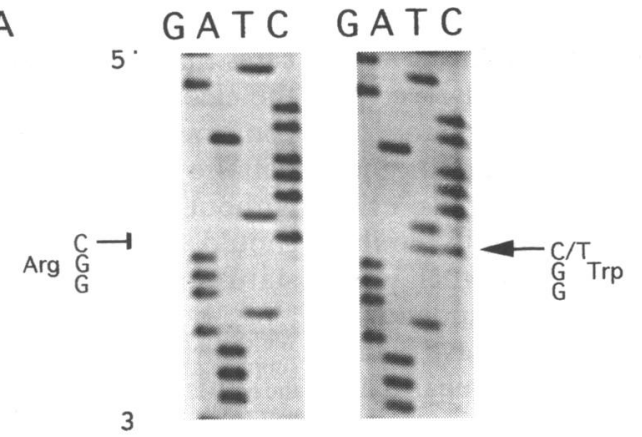

B

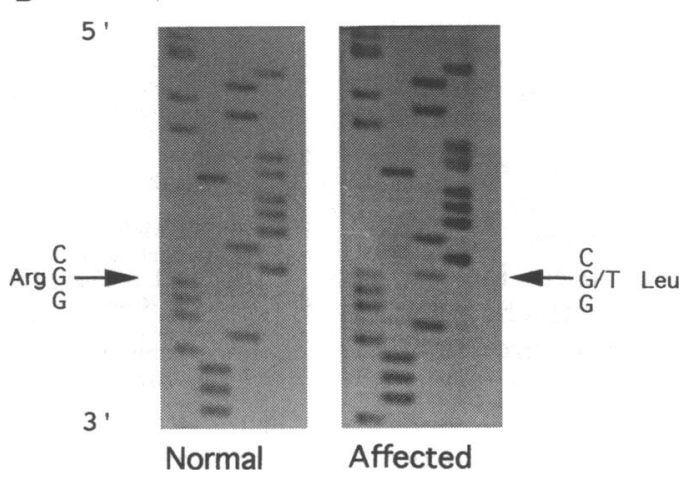

(fig 4A, control). The loss of the Ava I site caused by the mutation detected in this family generates an additional 139 bp fragment, corresponding to the uncut mutant allele (Fig $4 \mathrm{~A}, \mathrm{III} / 3$ ).

In addition to the proband, the mutation was also detected in two family members in whom HCM was diagnosed in the course of family screening - individuals $\mathrm{I} / 1$ and $\mathrm{II} / 2$. They both showed signs and symptoms consistent with HCM. Individual III/5, a 9 year old sibling who had an equivocal diagnosis also has the mutation. Strikingly, it was also detected in III/2, the proband's 22 year old sister. She remains symptom free and is clinically normal. Carrier status was inferred in both III/ 2 and III/5 from the genotype analysis of the polymorphic microsatellite sequence MYH7/I24 in an earlier study. ${ }^{12}$

Conversion of the arginine residue at position 403 to tryptophan was identified as the mutation in family B. After the mutation was confirmed in the proband (III/2, fig 4B) the substitution was detected in III/ 1 in whom HCM had been diagnosed during routine screening. Of the remaining relatives, three individuals, in whom diagnosis based on the isolated presence of electrocardiographic abnormalities had been equivocal, were also shown to be carriers. Finally, the mutation was also identified in the proband's 28 year old cousin (III/3), who showed no evidence of the condition.

The second mutation, a conversion of arginine to leucine, also in codon 403, was detected in family $C$ (fig $4 \mathrm{C}$ ). The mutation was detected in the proband (III/5), her sibling (III/4), and maternal uncle (II/1), who were not diagnosed until routine screening. Individuals II/4, III $/ 1, \mathrm{III} / 2$, and III/3 also carry the mutation. In these individuals the diagnosis of HCM based on isolated electrocardiographic abnormalities was regarded as equivocal.

\section{Discussion}

Geisterfer-Lowrance et al reported that mutation in codon 403 of the cardiac $\beta$ myosin heavy chain gene causes HCM. ${ }^{17}$ Our identification of two new mutations within this codon supports the suggestion that it is a mutation hot spot. ${ }^{18}$ However in the absence of a consistent correlation between phenotype and mutation within this codon, the biological significance of this observation remains to be established.

In the three families that we report there was a striking lack of phenotypic concordance with the specific mutations. Watkins et al suggested that the nature of the mutation may predict prognosis, such as predisposing carriers to a likelihood of sudden death. ${ }^{4}$ In the present three families, however, sudden death had occurred only in family $B$, despite the families having non-conservative mutations. This contrasts with the poor prognosis associated with the arginine $\rightarrow$ glutamine mutation in this same codon. The geographical proximity of the two Polish families may indicate a founder effect, although a common ancestor has yet to be identified.

The expression of the genetic defect was highly variable. HCM was diagnosed in first degree relatives by routine screening. Several

C

Figure 4 Digestion of the amplified product of exon 13 with Ava I in the three pedigrees studied. Products were digested at $37^{\circ} \mathrm{C}$ for $4 \mathrm{~h}$ and resolved on $2 \%$ agarose $2 \% \mathrm{NuSieve.} \mathrm{Digestion} \mathrm{of} \mathrm{the} \mathrm{PCR} \mathrm{product} \mathrm{from} \mathrm{normal} \mathrm{individuals} \mathrm{generates} \mathrm{two} \mathrm{fragments-90} \mathrm{and} 49$ bp. Abolition of an Ava I site by the two mutations results in the detection of an additional $139 \mathrm{bp}$ fragment.

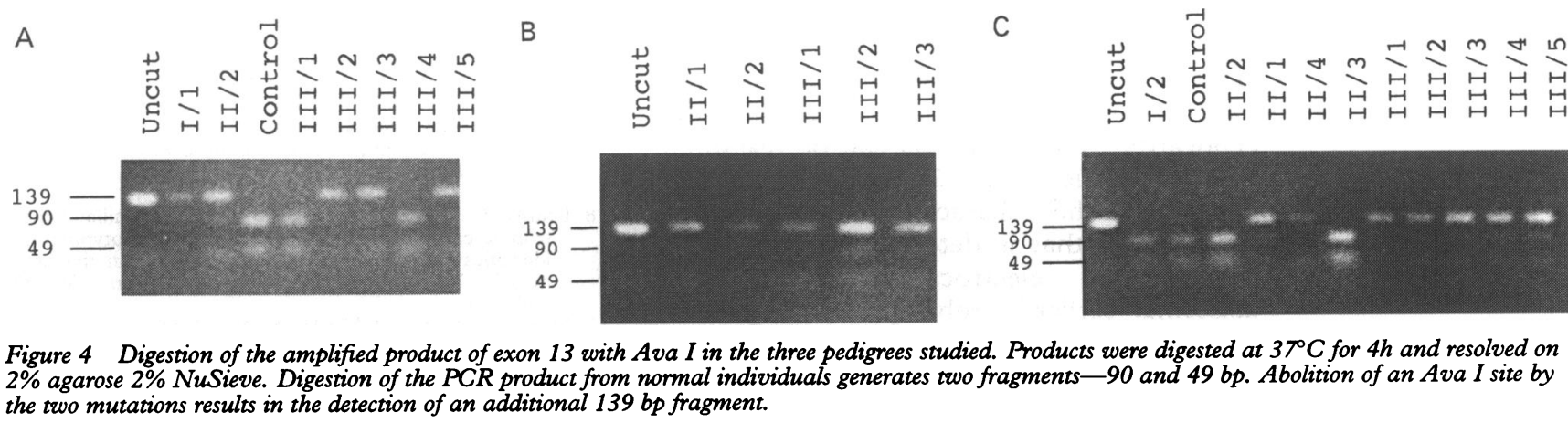


of the adults were largely symptom free but showed clear electrocardiographic and echocardiographic evidence of the disease. A mutation was also detected in family members with an abnormal electrocardiogram in the absence of definitive echocardiographic evidence. Though this is not surprising in family $A$, in which III/5 the proband's brother was only nine years old, ${ }^{19}$ several of these individuals are over 50 years old and would have been expected to have fully developed clinical features of the disease.

Two clinically unaffected individuals (family A - III/2 and family B-III/3), aged 22 and 28 years respectively, were identified as carriers of the mutation. This is especially surprising in view of the severity of the disease within the same generation in each family (IVSWT $\geqslant 27$ $\mathrm{mm}$ ), including a case of sudden death in family $\mathbf{B}$.

Understanding the basis of this variability of expression is just as important as identifying the underlying mutations. Several explanations have been propsed including gene regulatory mechanisms which modify phenotypic expression ${ }^{20}$ and environmental factors such as hypertension ${ }^{21}$ or athletic training. ${ }^{22}$

The electrocardiographic changes associated with HCM are variable ${ }^{23}$ and nonspecific. In these three families we have found that the electrocardiogram was a more sensitive marker of carrier status than wall thickness measured on the echocardiogram. Various changes were seen on the electrocardiogram: left ventricular hypertrophy, Q waves, or ST/T changes. Electrocardiograms from individuals with an equivocal diagnosis and those with overt HCM were similar, though $\mathrm{Q}$ waves were more common in those with an equivocal diagnosis ( $88 \%$ vs $25 \%$ ). The exact significance of this is unclear.

Counselling of carriers, who until now have been given a tentative diagnosis of HCM or more importantly have even been told that they are unaffected, must be carefully considered. We cannot predict the outcome in clinically unaffected individuals and the psychological impact of being told the genetic diagnosis can be extremely disturbing. Sudden death has occurred in patients without left ventricular wall thickening in whom classic myocardial fibre disarray was found at necropsy. ${ }^{24}$ None was known to have had a normal electrocardiogram. Because there are no recorded cases of sudden death occurring in an individual with a normal electrocardiogram, adults who are genetic carriers but who have normal electrocardiographic and echocardiographic findings can be reassured. Those aged less than 20 may not yet have developed the characteristic macroscopic hypertrophy that is detected by echocardiography; the electrocardiogram becomes abnormal earlier ${ }^{25}$ probably reflecting disarray. Carriers with abnormal electrocardiograms need serial follow up examinations.

Finally, the evidence of incomplete expres- sion of the genetic defects presented here indicates that more importance should be given to the electrocardiogram. When HCM has been confirmed within a family, we believe that a definite electrocardiographic abnormality, without an alternative clinical explanation, should be regarded as diagnostic for carrier status in first degree relatives.

We thank Dr Ketty Schwartz and Dr Pascale Guicheney for supplying their paper on a mutation hot spot in codon 403 of the MYH7 gene before publication and for their interest in this work. We also thank Mr Jaime Carvajal for his computation skills and time. This study was partially funded by CORDA.

1 Maron BJ, Bonow RO, Cannon RO III, Leon MB, Epstein SE. Hypertrophic cardiomyopathy: Interrelations of clinical manifestations, pathophysiology and therapy. $N$ Engl f Med 1987;316:780-9,844-52.

2 Davies MJ. The current status of myocardial disarray in hypertrophic cardiomyopathy. $\mathrm{Br}$ Heart $\mathcal{f} 1984 ; 51$ : 361-3.

3 Jarcho JA, McKenna W, Pare JAP, et al. Mapping a gene for familial hypertrophic cardiomyopathy to chromosome 14ql. N Engl F Med 1989;321:1372-8.

4 Watkins H, Rosenzweig A, Hwang D-S, Levi T, McKenna W, Seidman CE, Seidman JG. Characteristics and prognostic implications of myosin missense mutations in familial hypertrophic cardiomyopathy. $N$ Engl $7 \mathrm{Med}$ 1992;326:1108-14.

5 Epstein ND, Cohn GM, Cyran F, Fananapazir L. Differences in clinical expression of hypertrophic cardiomyopathy associated with two distinct mutations in the beta-myosin heavy chain gene. A $908^{\text {Lew-Val }}$ and a the beta-myosin heavy chain gene. A 908

6 Watkins $\mathrm{H}, \mathrm{McR}$ ae $\mathrm{C}$, Thierfelder $\mathrm{L}$, et al. A disease locus for hypertrophic cardiomyopathy maps to chromosome for hypertrophic cardiomyopathy

7 Carrier L, Hengstenberg C, Beckman JS, et al. Mapping of a novel gene for familial hypertrophic cardiomyopathy to chromosome 11. Nature Genet 1993;4:311-3.

8 Thierfelder L, MacRae C, Watkins H, et al. A familial hypertrophic cardiomyopathy locus maps to chromo some 15q2. Proc Natl Acad Sci USA 1993;90:6270-4.

9 Mares A, Marian AJ, Yu Q-T, et al. Genetic screening of 75 families with hypertrophic cardiomyopathy show missense mutations the most common genetic defect. Circulation 1992;86(suppl I):I-228.

10 Nishi H, Kimura A, Harada H, Toshima H, Sasazaki T. Novel missense mutation in cardiac beta-myosin heavy chain gene found in a Japanese patient with hypertrophic cardiomyopathy. Biochem Biophys Res Commun 1992; 188:379-87.

11 Perryman MB, Yu Q-T, Mares A, Czernuszewicz G Ifegwu J, Hill R, Roberts R. Expression of a missense mutation in myocardial tissue in hypertrophic cardiomyopathy. $₹$ Clin Invest 1992;90:271-7.

$12 \mathrm{Al}$-Mahdawi $\mathrm{S}$, Chamberlain $\mathrm{S}$, et al. Identification of a mutation in the beta-cardiac myosin heavy chain gene in a family with hypertrophic cardiomyopathy. Br Hear $\mathcal{F}$ 1993;69:136-41.

13 Rowlands DJ. The resting ECG. In: Julian DG, Camm AJ, Fox KM, Hall RJC, Poole-Wilson PA, eds. Diseases of, Fox KM, Hall RJC, Poole-Wilson PA, eds. Diseases

14 Liew CC, Sole MJ, Yamauchi-Takihara K, Kellman B, Andreas DH, Lin L, Liew JC. Complete sequence and Andreas $\mathrm{DH}$, Lin $\mathrm{L}$, Liew JC. Complete sequence and organisation of the human cardiac beta myos
chain gene. Nucleic Acids Res 1990;18:3647-51.

15 Hultman T, Stahl S, Hornes E, Uhlen M. Direct solid phase sequencing of genomic and plasmid DNA using magnetic beads as solid support. Nucleic Acids Res 1989;17:4937-46.

16 Jaenicke T, Diederich KW, Hass W, Schleich J, Lichter $P$ Vosberg H-P. The complete sequence of the human beta myosin heavy chain gene and a comparative analysis of its product. Genomics 1990;8:194-206.

7 Geisterfer-Lowrance AA, Kass S, Tanigawa G, Vosberg H-P, McKenna W, Seidman CE, Seidman JG. A molecular basis for familial hypertrophic cardiomyopathy: A beta cardiac myosin heavy chain gene missense mutation. Cell 1990;62:999-1006.

18 Dausse E, Komajda M, Felter L et al. Familial hypertrophic cardiomyopathy: microsatellite haplotyping and identification of a hot-spot for mutations in the betamyosin heavy chain gene. $₹$ Clin Invest 1993;92 $2807-13$.

19 Maron BJ, Spirito P, Wesley Y, Arce J. Development and progression of left ventricular hypertrophy in children with hypertroph

20 Lompre AM, Mercadier J, Schwartz K. Changes in gene 
expression during cardiac growth. Int Rev Cytol 1991;124:137-86.

21 Karam R, Lever HM, Healy BP. Hypertensive hypertrophic cardiomyopathy or hypertrophic cardiomyopathy with hypertension? A study of 78 patients. $\mathcal{F} \mathrm{Am} \mathrm{Col}$ Cardiol 1989;13:580-4.

22 Gilligan D, Cleland J, Oakley C. The clinical and genetic heterogeneity of hypertrophic cardiomyopathy. Current Medical Literature-Cardiovascular Medicine 1990;9: 155-61.

23 Maron BJ, Wolfson JK, Ciro E, Spirito P. Relation of electrocardiographic abnormalities and patterns of left ven- tricular hypertrophy identified by two dimensional echocardiography in patients with hypertrophic cardiomyopathy. Am $\mathcal{F}$ Cardiol 1983;51:189-94.

24 McKenna W, Stewart JT, Nihoyannopoulous P, McGinty F, Davies MJ. Hypertrophic cardiomyopathy without hypertrophy; two families with myocardial disarray in the absence of increased myocardial mass. Br Heart 1990;63:287-90.

25 Panza JA, Maron BJ. Relation of electrocardiographic abnormalities to evolving left ventricular hypertrophy in hypertrophic cardiomyopathy during childhood. $A m f$ Cardiol 1989;63:1258-65.

\section{ABSTRACTS IN CARDIOLOGY}

\section{Prevention of root dilatation in Marfan's syndrome}

Prophylactic replacement of a dilating aortic root to forestall dissection is an accepted form of management in Marfan's syndrome but there is now clear evidence, in the article by Shores $e t$ al, that the need for surgery can be reduced by long-term $\beta$ adrenergic blockade. Such evidence was needed. The doses used to achieve a negative inotropic effect, and theoretically reduce risk, are high. To expose young people to long-term side effects without proven benefit is not justifiable.

The problem of dissection in Marfan's syndrome is not totally solved however. In some patients dissection occurs before the aorta dilates and even in those on $\beta$ blockade aortic dilatation continues, albeit at a slower rate. We are, however, closer to rational therapy.

M J DAVIES

\section{Progression of aortic dilatation and the benefit of long-term $\beta$-adrenergic blockade in Marfan's syndrome}

Jennifer Shores, Kenneth R Berger, Edmond A Murphy, Reed E Pyerizz

Backprownd-The aortic root enlarges progressively in Marfan's syndrome, and this ealargement is associated with aortic regurgitation and dissection. Long-term treatment with $\beta$-adrenergic blockade, by reducing the impulse (i.e., the rate of pressure change in the aortic root) of left ventricular ejection and the heart rate, may protect the aortic root. Methods-We conducted an open-label, randomized trial of propranolol in adolescent and adult patients with classic Marfan's syndrome ( 32 treated and 38 untreated [control patients). Aortic-root dimensions and clinical end points (aortic regurgitation, aortic dissection, candiovascular surgery, congestive heart failure, and death) were monitored for.an average of 9.3 years in the control group and 10.7 years in the treatment group. All 70 patients were included in the analysis according to the intention-to-treat principle.
Resulks - The dose of propranolol was individualized: the mean ( \pm SE) dose was $212 \pm 68 \mathrm{mg}$ per day. The mean slope of the regression line for the aortic-root dimensions, which reflect the rate of dilatation, was significantly lower in the treatment group than in the control group $10.023 v 0.084$ per year, $P<0.001)$. Clinical end points were reached in five patients in the treatment group and nine in the control group. The Kaplan-Meier survival curve for the treatment group differed significantly from that for the control group during the middle years of the trial and remained better for the treatment group throughout the study.

Conclusions-Prophylactic $\beta$-adrenergic blockade is effective in slowing the rate of aortic dilatation and reducing the development of aortic complications in some patients with Marfan's syndrome. (N Engl I Med 1994;330:1335-41). 
Patients with aortic root abscess usually show extension to adjacent structures and dehiscence of the prosthetic valve. ${ }^{1}$ Early surgical intervention with scrupulous debridement of all infected material and reconstruction of the aortic root with a homograft or autologous or heterologous patch is the recommended treatment. The use of an aortic homograft has been reported to be particularly promising; Glazier et al reported that only two of their 21 hospital survivors had recurrence of endocarditis after homograft aortic root replacement. ${ }^{5}$

Our patient was unusual because transoesophageal echocardiography showed that the abscess persisted for two days after operation. The abscess may have extended too far into the adjacent structures to permit thorough debridement.

We thank Dr Jakob Schneider, Institute of Pathology, University Hospital, Zurich for providing the prepared specimens shown in figures 3 and 4 .

1 Arnett EN, Roberts WC. Valve ring abscess in active infective endocarditis. Frequency, location and clues to clinical diagnosis from the study of 95 necropsy patients. Circulation 1976;54:140-5.

2 David TE, Komeda M, Brofman PR. Surgical treatment of aortic root abscess. Circulation 1989;80:I 269-74.

3 Mulcahy D, Shapiro LM, Westgate C, Ross DN, Donaldson RM. The diagnosis of aortic root abscess by cross-sectional echocardiography. Clin Radiol 1986;37: 235-8.

4 Cowan JC, Patrick D, Reid DS. Aortic root abscess complicating bacterial endocarditis. Demonstration by computed tomography. Br Heart $\mathcal{F}$ 1984;52:591-3.

5 Glazier J, Verwilghen J, Donaldson RM, Ross DN. Treatment of complicated prosthetic aortic valve endocarditis with annular abscess formation by homograft aortic root replacement. F Am Coll Cardiol 1991;17: 1177-82.

\section{CORRECTION}

The electrocardiogram is a more sensitive indicator than echocardiography of hypertrophic cardiomyopathy in families with a mutation in the MYH7 gene $S \mathrm{Al}$ Mahdawi, S Chamberlain, L Chojnowska, E Michalak, $P$ Nihoyannopoulos, M Ryan, B Kusnierczyk, f A French, D M Gilligan, $\mathcal{f}$ Cleland, $R$ Williamson, W Ruzyllo, C Oakley.

We regret that the traces for leads V1 to V6 in an electrocardiogram in fig 2 of this article ( $B r$ Heart $\mathcal{f}$ 1994;72:105-11) were incorrectly mounted during relabelling. The correct version of this trace is reproduced below.

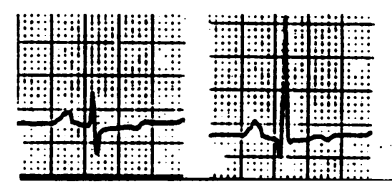

I

V1

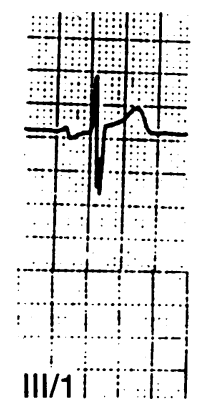

II

V2

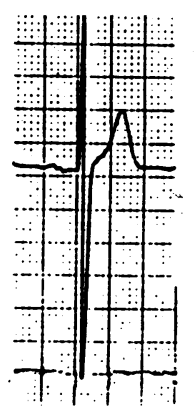

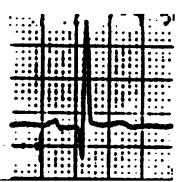

III

V3

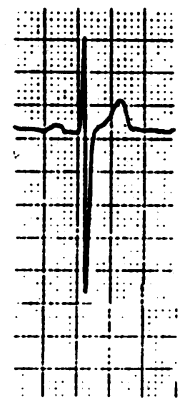

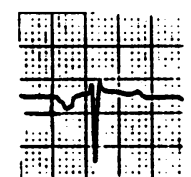

aVR

V4

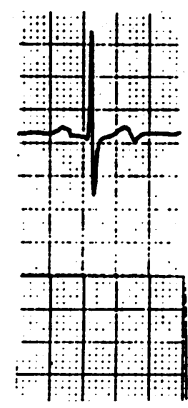

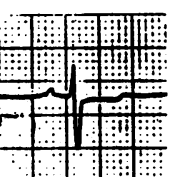

aVL

V5

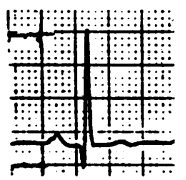

aVF

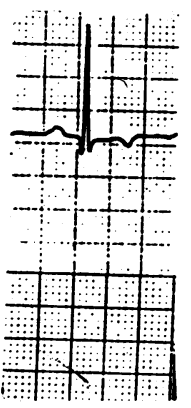

V6

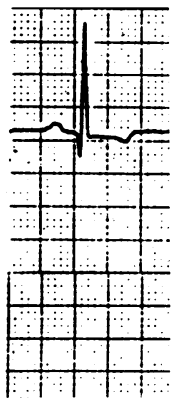

